\title{
LOS VIAJEROS DECIMONÓNICOS: FORJANDO LA IDEA DEL PAISAJE MEXICANO
}

\author{
TRAVELERS FROM THE NINETEENTH CENTURY: FORGING THE MEXICAN LANDSCAPE MINDSET
}

\author{
Juan Pablo Angulo Partida
}

\section{Resumo}

El paisaje es entendido como una producción cultural, una manera de ver y representar al mundo circundante. Desde esta perspectiva, el presente artículo pretende explorar las representaciones del paisaje que ayudaron a forjar la imagen del México decimonónico. Tomando en cuenta lo anterior, se seleccionaron obras de viajeros que van desde especialistas como Humboldt, hasta aficionados. En dichos textos, se abordaron aspectos como el papel de la religión en el paisaje, la representación de México como el cuerno de la abundancia, la incipiente perspectiva científica, la representación de la tropicalidad, y la producción estética del paisaje mexicano. Las representaciones del paisaje presentadas en este artículo, corresponden a la perspectiva de Occidente, la cual no tomaba en cuenta a otros modelos culturales. Estas representaciones dieron lugar al paisaje mexicano, que no era americano ni europeo, el cual sirvió en la construcción del nacionalismo mexicano.

Palabras clave: Paisaje mexicano. Viajeros decimonónicos. Paisaje del siglo XIX

\section{ABSTRACT}

The landscape is understood as a cultural production, a way of seeing and representing the surrounding world. From this perspective, this article aims to explore the representations of the landscape that helped to forge the image of the nineteenth-century Mexico. Taking into account the above, texts written by travelers, ranging from specialists such as Humboldt, to amateurs, were selected. In these texts, aspects such as the role of religion in the landscape, the representation of Mexico as the horn of abundance, the incipient scientific perspective, the representation of tropicality, and the aesthetic production of the Mexican landscape, were addressed. The representations of the landscape, presented in this article, correspond to the perspective of the West, which did not take into account other cultural models. These representations gave rise to the Mexican landscape, which was no longer American or European, and served in the construction of the Mexican nationalism.

Keywords: Mexican landscape. Nineteenth-century travelers. 19th-century landscape 


\section{INTRODUCCIÓN}

El objetivo de este artículo es explorar las representaciones contenidas en la literatura científica y descriptiva de viajeros, que a lo largo del siglo XIX contribuyeron a la concepción del paisaje mexicano en Occidente. Antes de exponer las diferentes representaciones del paisaje mexicano del siglo XIX, es preciso definir qué se entiende como paisaje. El concepto de paisaje es multifacético, debido a la cantidad de perspectivas que se han empleado para su estudio. Para John B. JACKSON (1984, p.3), el paisaje es la porción de tierra que la vista humana puede abarcar; además, desde una perspectiva estética, se pueden seleccionar aquellos elementos considerados pintorescos, dejando de lado otros que no lo son, como los caminos lodosos, los campos arados, las aldeas escuálida, entre otros. Así, generalmente se considera al sujeto como un elemento activo en la existencia ontológica del paisaje. De acuerdo con Jean-Marc BESSE (2010), para que exista el paisaje, el observador tiene que alejarse lo suficiente para percibirlo y pensarlo, además de escoger los componentes que considere más relevantes en dicho espacio, y así, construir una composición pictórica.

A pesar de que las definiciones clásicas presentan al paisaje como la parte del territorio que aparece a la vista de un espectador, generalmente desde un sitio elevado; autores como Jean-Marc BESSE (2011, p.10), agregan que el paisaje ya no debe entenderse como una realidad objetiva, sino como una manera de ver y representar al mundo circundante. Para BESSE (2010), el paisaje es una producción cultural, es decir, "las proyecciones de la cultura sobre el país". Por su parte, Agustin BERQUE (2009) asegura que la idea del paisaje se asocia a la clase dominante, a aquellas personas que fueron capaces de separarse de la labor para permitirse observar el entorno y la naturaleza. Estos grupos elitistas utilizaron los discursos sobre el paisaje para construir imaginarios nacionales o incluso coloniales, en los cuales la nación fue identificada con un espacio natural con evidente permanencia en el tiempo, la cual ha trascendido en la historia de los pueblos (Grohnert, 2013, p.74), aspecto que guarda relevancia con el presente artículo.
Para BERQUE (2009), el paisaje no ha estado presente a lo largo de la historia de la humanidad. En el caso de Occidente, fue a partir del Renacimiento cuando el paisaje cobró relevancia para los europeos, ya que en la Edad Media, la ortodoxia agustiniana prohibía el disfrute profano del entorno, aspecto que comenzó a cambiar a partir del siglo XV en Flandes y en Italia, con la contemplación del ambiente y su representación pictórica (BERQUE, 1997 , p.9). Por esta razón, en este trabajo, la perspectiva del paisaje solo corrió a cargo de la clase elitista, la cual contaba con la capacitación intelectual y el tiempo para la contemplación y movilidad. Todos los autores aquí expuestos, a pesar de tener ocupaciones y procedencias distintas, seguían una misma línea de pensamiento, una manera particular de ver y valorar al paisaje, lo que Agustin BERQUE (2009) denominó el "paradigma occidental moderno clásico" (POMC).

El análisis que se realizó en este artículo se enfocó en diferentes concepciones del paisaje. Las dos más aludidas, fueron las referentes a los elementos del entorno y a su representación, ya sea desde imágenes o con palabras. La primera está enfocada en la medición, y la segunda es un acercamiento estético (BERQUE, 1997, p.7-8). Al respecto, los autores culturalistas se han opuesto a que el paisaje sea entendido como una realidad territorial objetiva, por el contrario, abogan en poner más énfasis en cómo es representado (BESSE, 2010).

Ante la problemática de definir al paisaje, Jean-Marc Besse identificó la heterogeneidad del concepto desde diferentes enfoques a través de la historia, los cuales corresponden a aspectos prácticos, a intereses personales y a las distintas disciplinas que han estudiado el paisaje (BESSE, 2006, p.146). La primera de estas perspectivas, y quizá la más conocida, afirma que el paisaje es una representación cultural, que debe ser estudiada desde el análisis del discurso, para así, identificar los sistemas filosóficos, estéticos y morales que lo sustentan (BESSE, 2006, p.147). Para esta perspectiva, los artistas serían los únicos creadores de paisajes (BESSE, 2006, p. 150).

La siguiente perspectiva ve al paisaje como un territorio objetivo, material, fabricado y habitado, el cual ha sido modificado por 
las prácticas económicas, políticas y culturales de las personas. John Brickerfhoff Jackson defendió a este enfoque geográfico, por entender al paisaje como un espacio organizado y como la obra colectiva de las sociedades que han transformado el sustrato natural (BESSE, 2006, p. 151 y 152). La tercera perspectiva ve al paisaje como el entorno material y vivo de sociedades humanas siempre cambiantes, la ecúmene humana, definiendo al paisaje como un sistema o entidad medial, en donde todos los elementos interactúan de manera dinámica y variable (BESSE, 2006, p.158). El paisaje también es entendido como una experiencia fenomenológica, es decir, la vivencia de cada individuo al relacionarse con el entorno; desde esta perspectiva, el paisaje en primer lugar se vive y después se describe (BESSE, 2006, p. 161).

Finalmente, el paisaje también es visto como un proyecto, en donde éste es un palimpsesto de varias intervenciones humanas. Desde esta postura, se cuestiona el estado del entorno, y se proponen posibles contenidos en lo real. Entonces, "proyectar el paisaje sería a la vez ponerlo en imágenes o representar (proyección) e imaginar lo que podría ser o llegar a ser" (BESSE, 2006, p. 168). En este artículo se presentan todos estos enfoques, a través de los textos de diferentes personajes que representaron al paisaje mexicano bajo sus concepciones estéticas, o entendiéndolo como un territorio modificado por prácticas culturales, como un sistema, una experiencia, o un proyecto de intervención.

La importancia de estudiar al paisaje, de acuerdo con Agustin BERQUE (1996, p. 9), se debe a que "las sociedades utilizan y transforman su entorno en función de las representaciones que de él se hacen, y viceversa, interpretadas en función de sus prácticas materiales". Por lo que es relevante conocer la representación del paisaje para así entender cómo éste fue y es modificado.

\section{El paISAJe MEXICANO}

El paisaje mexicano decimonónico fue representado ${ }^{1}$ en la mentalidad de Occidente, concebido, ya sea como una zona desérticae inhóspita, una selva tropical abundante en flora y fauna, o un paraíso (Imagen 1). Pero estas consideraciones del paisaje tienen un largo antecedente. Después de que la Nueva España lograra su independencia, muy poco se sabía de las tierras mexicanas, tan solo unos años antes de que Miguel Hidalgo diera el grito de Dolores, el afamado explorador y naturalista Alexander von Humboldt había pisado México, y no solo eso, sino que promovió a la nueva nación en el extranjero, llevando a Europa y a Estados Unidos sus escritos que versaban sobre las tierras mexicanas.

Los siglos XVIII y XIX, se caracterizaron por una gran ola de nuevas exploraciones, el propio Humboldt fue influenciado por Malaspina (1788-94), Cook (1768-79) y otros exploradores. Pero, en estos viajes, la llustración y al auge de la ciencia proporcionaron las herramientas necesarias para que los ojos de los europeos no se limitaran al paisaje aparente, sino que lo desmembraban para estudiarlo y registrarlo. Fue Humboldt, quien al menos en México, pudo combinar las descripciones geográficas con el registro de datos científicos, como altura, presión y temperatura, sin dejar de lado el funcionamiento del paisaje como un todo.

Las observaciones que realizó Humboldt, y que están plasmadas en sus obras acerca de México, sobrevivieron como representaciones del paisaje mexicano en la mente de viajeros sucesivos. Fue así, que las representaciones que surgieron a partir de Humboldt, permanecieron y se vieron reflejadas en obras posteriores. Esto no quiere decir que Humboldt haya sido el autor indiscutible del paisaje mexicano, ya que antes de su viaje, él leyó todo lo posible con respecto a las colonias españolas (BECK, 1971).

Es preciso especificar que los viajeros aquí citados no se limitaron al paisaje intervenido por el humano, es decir a las ciudades y poblaciones, cultivos, industrias, caminos, etcétera; sino que también hicieron referencia al paisaje prístino y virgen, en donde el humano no había podido domar a la naturaleza. Entonces, en este

La representación social es un concepto de Durkheim retomado por S. Moscovici en 1961. Se refiere a la elaboración por parte de una colectividad, bajo inducción social, de una concepción de la tarea que no toma en consideración la realidad de su estructura funcional. Esta representación incide directamente sobre el comportamiento social y la organización del grupo y llega a modificar el propio funcionamiento cognitivo. Denise Jodelet. "La representación social: fenómenos, conceptos y teorías." En Psicología social l: influencia y cambio de actitudes, individuos y grupos, 470. Barcelona, España: Paidós, 1985. Pág. 470. 


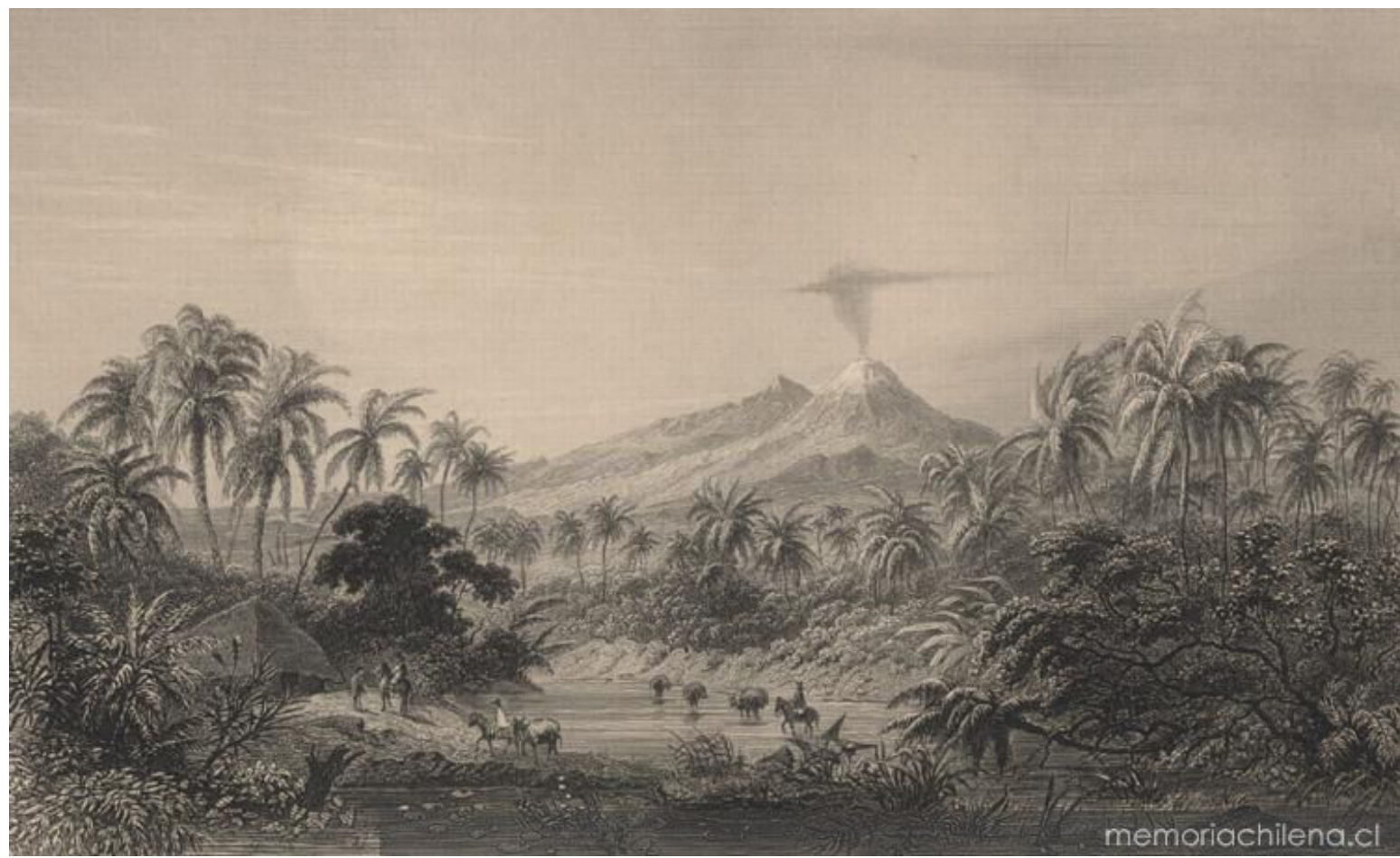

Imagen 1. Vegetación de la costa oeste, palmeras y volcanes de Colima, Rugendas, 1840

Obra localizada en la Biblioteca Nacional de Chile, pertenece al patrimonio cultural común. ${ }^{2}$

texto, hablar de naturaleza, implica todo aquello que no haya sido manufacturado, intervenido o domesticado por el humano.

El corpus documental que se empleó para identificar a las representaciones sobre el paisaje mexicano, incluye obras de diversos viajeros que surcaron el camino entre el puerto de Veracruz a la ciudad de México y sus alrededores, y en algunos casos se involucraron a los puertos de Acapulco y Manzanillo, así como a la ciudad de Colima. Además, se trató de tener una visión heterogénea no solo del paisaje, sino de quién lo describió, así, en este artículo se representa la postura del europeo nacido en Europa que vive en México, el europeo radicado en Europa pero que visita México, el mexicano culto, el naturalista decimonónico, e incluso la perspectiva de tres mujeres. Con ello, se pretende identificar las

2 Biblioteca Nacional de Chile (BNC), Patrimonio cultural común, Vegetation of the westcoast, Palm-wood and volcano of Colima, Mauricio Rugendas 1840, id MC: MC0007347 en http://www.memoriachilena.cl/602/w3-article-67979.html coincidencias y las diferencias entre las representaciones elaboradas por personajes de distintas realidades sociales. Sin olvidar que la representación del paisaje en el siglo XIX corrió a cargo de solo aquellas personas que por su nivel económico y posición social podían acceder a la instrucción educativa.

Tomando en cuenta lo anterior, los viajeros y las obras consultadas fueron seleccionados con el fin de abarcar todo el espectro de las representaciones del paisaje, desde especialistas como Humboldt, hasta aficionados como la dama de compañía de la emperatriz Carlota. Además, las representaciones del paisaje fueron generales, regionales e incluso muy puntuales. Considerando lo anterior, las obras consultadas fueron: Cosmos (1845-1862) y Ensayo político sobre el Reino de la Nueva España (1811) de Alexander von Humboldt; Obras del Lic. Don Alfredo Chavero (1864) de Alfredo Chavero; Un viaje a México en 1864 de Paula Kolonitz; México hacia 1850 de Carl Christian Sartorius; Viaje a 
México (1844) por Mathieu de Fossey; Viajes por México en los años 1845-1848 por Carl Bartholomaeus Heller; y La vida en México durante una residencia de dos años en ese país (1843) de Frances Erskine Inglis también conocida como Marquesa de Calderón de la Barca; así como las obras pictóricas de la pintora colimense Senorina Merced Zamora.

En los textos enumerados, se reconocieron ciertas tendencias entre las representaciones del paisaje. Se identificó que en los relatos se describían las características sociales de la población, como la importancia de la religión para entender el origen del paisaje, la representación de México como el cuerno de la abundancia, la incipiente perspectiva científica, la representación de la tropicalidad y sus peligros, y la producción artística y estética del paisaje mexicano. A continuación, se exponen cada uno de los aspectos que los viajeros emplearon en sus textos, sin que la intención sea hacer una descripción exhaustiva del paisaje mexicano, sino más bien, de las ideas que favorecieron a cada una de sus representaciones.

\section{La Naturaleza como algo divino.}

Un tipo de representación contenida en algunas descripciones de viajeros, guarda relación cercana con la tradición judeocristiana. Las posturas religiosas fueron ambivalentes, ya que la mayoría de estos viajeros provenían de países no católicos, incluso, algunos viajeros se alegraron de la ausencia de fanatismo religioso en algunos sitios de México, mientras que otros veían como algo positivo la llegada del cristianismo al país. Para entonces, la línea divisoria entre la religión y la ciencia era más permeable. Por ejemplo, una descripción meramente científicas de la segunda mitad del siglo XIX elaborada por el ingeniero Eduardo Harcort, hizo referencia a un evento bíblico, el diluvio (HARCORT, 1831), como parte de una explicación científica de la época.

HUMBOLDT (1845, p.134), por su parte, realizó una apología del papel de la religión en las exploraciones naturalistas, mencionó en su obra Cosmos, que "fue el cristianismo quien preparó los espíritus para que buscasen en el orden del mundo y en las bellezas naturales, el testimonio de la grandeza y excelencia del Creador". Así, este afamado naturalista creía que la tendencia a glorificar a la Divinidad, debió desarrollar también el gusto por las descripciones. Sin embargo, agregó Humboldt, que dicha afición no es el solo efecto de esta glorificación de la Divinidad por la entusiasta contemplación de la Naturaleza, sino que tal admiración siempre iba acompañaba del desprecio hacia las obras humanas $^{3}$. Humboldt comparó sus escritos con la labor descriptiva de los cristianos, al decir que ha procurado hacer "ver en el Cosmos, lo mismo que en los Cuadros de la Naturaleza, que la exacta y precisa descripción de los fenómenos no es absolutamente inconciliable con la pintura viva y animada de las imponentes escenas de la creación" (HUMBOLDT, 1845, p. IX).

Sin embargo, las posturas cristianas y judías han tenido diversas interpretaciones. Existe la ambivalencia en los textos bíblicos, en donde el pensamiento generalizado entre los cristianos es ver a los animales y a las plantas como seres sin alma, por lo tanto podían ser "mejorados" aumentando su utilidad y belleza4", es decir, justificaban la intervención del humano para modificar el paisaje. Por otro lado, otros pasajes bíblicos hacen referencia al cuidado de los recursos naturales, por ejemplo, Moisés recomendó, "cuando ataques una ciudad, no destruyas el bosque que lo rodea. El árbol no es tu enemigo" (ANZOLIN, 2006).

El resto de los viajeros tuvieron opiniones divergentes en cuanto a la presencia de la religión cristiana en México. Así, algunos afirmaron que las ideas religiosas afectaron a la conducta considerada "salvaje" de los indígenas americanos. Por ejemplo, Fossey afirmó que la propagación del Evangelio llevada a cabo por la Corona de Castilla, permitió poner fin a las "bárbaras costumbres de pueblos como el azteca, que habían ensuciado sus

\footnotetext{
3 Crisóstomo repite en muchos pasajes: Cuando veas un magnífico monumento y te encante el espectáculo de una larga columnata, dirige en seguida tus miradas hacia la bóveda del cielo, y á los campos libres donde pacen los rebaños cerca de las orillas de mar. Alexander von Humboldt. Cosmos. Berlín, 1845. Pág. 138.

4 Por ejemplo, las descripciones de un monje benedictino francés del siglo XII hablaba de que se había dado sentido al paisaje al poner orden donde había caos y diques en los ríos para abastecer las norias del convento, una verdadera factoría con telares, prensas, sierras, molinos, etcétera. Adriana Anzolin. Lazos verdes. Buenos Aires, Argentina:
} Editorial Maipue, 2006. Pág. 32 . 
creencias religiosas con el horror de los sacrificios humanos" (FERRER, s/f, p.134). Por su parte, Albert S. Evans lamentaba la llegada del cristianismo al nuevo mundo, al decir que "vinieron a difundir desolación y la religión de la cruz por tierras pacíficas e inofensivas" (EVANS, 1870; en ORTOLL, 1982, p.134). De igual forma, otros celebraban el olvido de costumbres religiosas, Chavero hizo referencia a ello al mencionar que "las costumbres basadas en ideas absurdas de preocupaciones religiosas, habían desaparecido en Colima" (CHAVERO, 1864, p.43). Igual impresión tuvo Viltold de Szyszlo, al mencionar que por su paso por el occidente mexicano, no encontró ningún indicio de fanatismo religioso (SZYSZLO, 1909; en ORTOLL, 1982, p.234). A pesar de estos comentarios, en las representaciones de paisajes culturales del occidente de México, aparecen templos católicos que formaron parte del paisaje (Imagen 2).

Los aspectos religiosos no precisamente se limitaron al cristianismo. Sartorius identificó una relación del humano con la naturaleza desde la visión espiritual indígena, que tenía la función de moldear las mentes de los pueblos. Ejemplo de ello fue la herencia cultural tolteca, la cual se manifestaba en la celebración de la fiesta de muertos en México, un sentimiento de vínculo religioso considerado pagano con la naturaleza, elemento que la generalidad de los indios mexicanos había preservado, y que se manifestaba en la prioridad que concedían a los arreglos florales como ornamentación religiosa (COVARRUBIAS, s/f, p.235).

\section{México, el CUERno de la abundancia.}

Una de las ideas más difundidas sobre México en las descripciones de Humboldt, fue la abundancia de sus recursos naturales. Punto de partida para que más viajeros consideraran a la joven patria como un lugar para ser explorado y explotado. Incluso la misma mexicanidad se basó en las obras de Humboldt para promover a México como un país privilegiado ${ }^{5}$. Situación que

5 Todos los mexicanos ilustrados de la época le profesaron un amor sin cortapisas. Lucas Alamán, el intelectual más distinguido de la primera mitad del siglo XIX, le escribió hacia 1825, en su calidad de Ministro de Negocios Extranjeros: "Por vuestras luminosas obras... puede formarse una idea de que México llegará a ser regido por una fue más evidente cuando Antonio López de Santa Anna premió a Humboldt en 1854 con la Gran Cruz de la Orden de Guadalupe, a lo que Humboldt respondió: "pude dar a conocer a Europa, con la publicación del Ensayo Político sobre México, el valor de las riquezas minerales y agrícolas del vasto país, cuya prosperidad, confiada a vuestra sabiduría, es el objeto de vuestra constante solicitud" (KRAUZE, 1994, p. 22). Con ello, Humboldt mostró al mundo, no solo la existencia de México, sino también sus riquezas. Al respecto, Lucas Alamán, en su Historia de México, sintetizó la trascendencia del ensayo del prusiano, al mencionar que "hizo conocer esta importante posesión a la España misma, a todas las naciones y a los mismos mexicanos" (KRAUZE, 1994, p. 22).

Medio siglo después de la visita de Humboldt a México, Paula Kolonitz también notó la riqueza del país. Esta dama de compañía de la emperatriz Carlota, estaba convencida de que "la tierra ayudaba, y por sus riquezas y por sus tesoros agrícolas y minerales, podría decirse que era la mejor del mundo" (KOLONITZ, 1864, p.158). Pero a la vez Kolonitz veía que en México "no sabían aprovechar los materiales que en abundancia ofrece el país", y con los cuales la esplendidez y la solidez se lograrían generosamente. Paula hizo notar que en las montañas mexicanas había bellísimo pórfido, y que en sus bosques crecían innumerables árboles de maderas preciosas, las cuales no se mostraban en los mobiliarios de las residencias (KOLONITZ, 1864, p.95). Para Kolonitz, era tal el desperdicio de recursos naturales, que creía que fácilmente se podrían realizar grandes proyectos. Por ejemplo, con la abundante humedad, se podrían construir canales subterráneos en diversos puntos del país y ofrecer así una magnífica vegetación, ya que como decía Kolonitz, "aquí la grandiosa naturaleza crea y da de todo" (KOLONITZ, 1864, p.103). buena constitución, ya que este país posee todos los elementos indispensables para su
prosperidad... su lectura no ha contribuido poco a avivar el espíritu de independencia prosperidad... su lectura no ha contribuido poco a avivar el espíritu de independencia
que germinaba en muchos de sus habitantes, y a despertar a otros del letargo en que los tenía la dominación extraña. La nación entera está pletórica de gratitud por vuestros trabajos". Krause. Enrique Krauze. "Humboldt y México un amor correspondido". Vuelta 212 (julio de 1994). Pág. 21. 


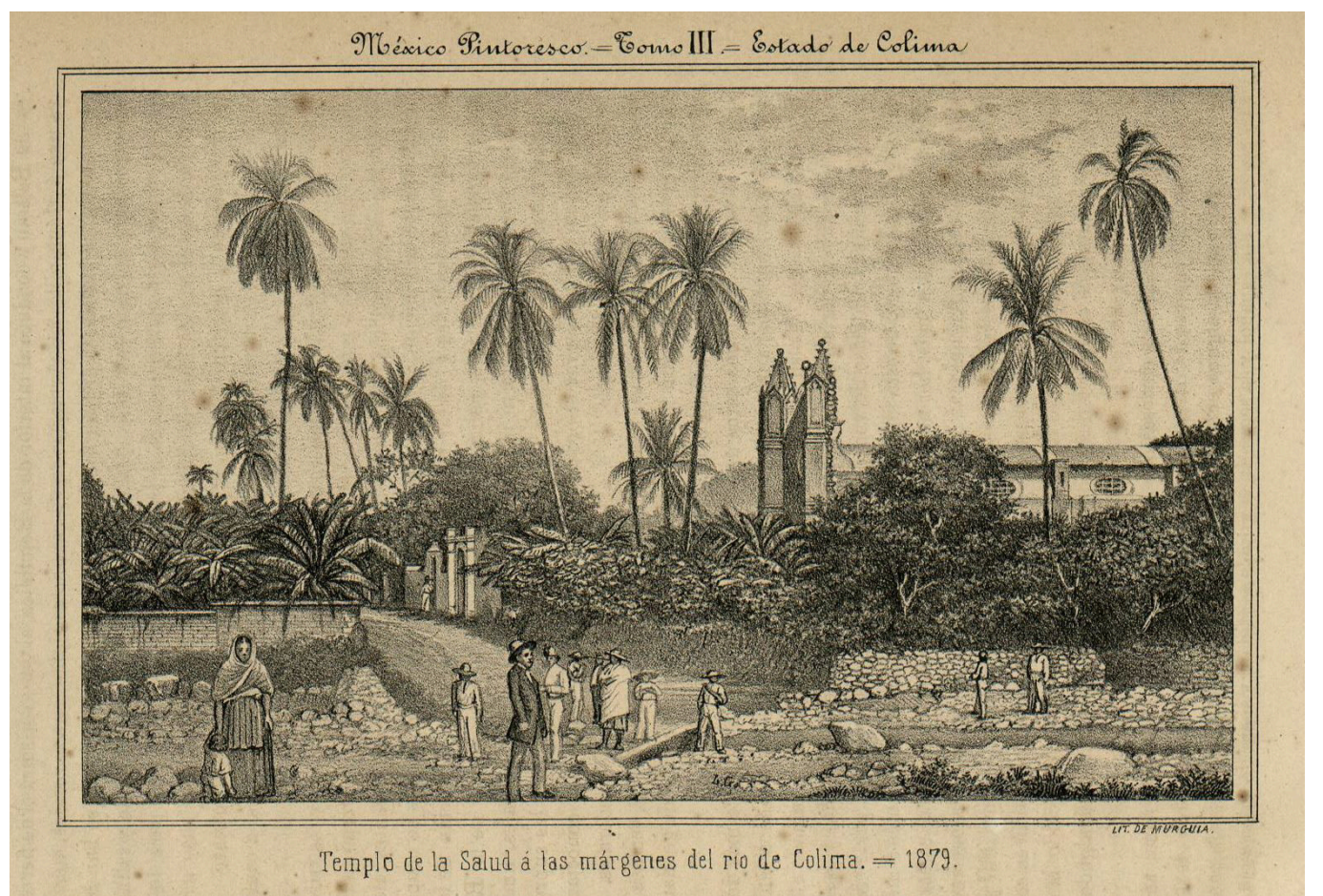

Imagen 2. Templo de la Salud a las márgenes del río de Colima, 1879

Litografía de Murguía en México Pintoresco,

Tomo III. Estado de Colima, 1880 (RIVERA, 1882,

p.597).

La idea del México rebosante de recursos naturales siguió vigente en los escritos de viajeros de mediados del siglo XIX. Albert $\mathrm{S}$. Evans en su visita al occidente mexicano, se percató de que los bosques de la región eran abundantes en caza, y las aguas abundantes en peces $^{6}$, sin mencionar la exuberancia de las frutas de los trópicos (EVANS, 1870; en ORTOLL, 1982, p.113). En la misma región, el licenciado Chavero agregó otras cualidades de las producciones locales, en donde las haciendas producían la mejor clase de arroz, añil, maíz, cacao, frijol, café, caña de azúcar y otros frutos, además de una famosa sal que ya es una riqueza. Chavero agregó, que la abundancia era tal, que el ébano servía de leña en los jacales (CHAVERO, 1864, p.54). Tal percepción de abundancia, propició el nacimiento de una incipiente industria

6 Pudiendo hallarse codornices, venados, pavos silvestres, faisanes, gallinetas de dos variedades, etc. este es un paraíso para el cazador, y las aguas de la bahía abundan en peces de todas las clases. Albert S. Evans (1870). Una visita de gala a Manzanillo y Colima, en Por Tierras de Cocos y Palmeras. Apuntes de Viajeros a Colima, Siglos XVIII a XX. México DF: Instituto José María Luis Mora y Offset, 1982. Pág. 112. textil en lugares tan alejados de la capital del país, como Colima, cuya infraestructura formó parte del paisaje local (Imagen 3).

Después de estas descripciones de exuberancia, diversos lugares de México no esperarían mucho para ser explotados. Albert S. Evans parecía estar completamente consciente de la importancia de las mejoras públicas y del desarrollo de los grandes recursos naturales del país (EVANS, 1870; en ORTOLL, 1982, p.116). Aspecto que también generó una extracción desmedida de los recursos locales, de esta forma, Viltold de Szyszlo presenció cómo una compañía francesa se constituyó para explotar los abundantes yacimientos de hierro descubiertos en las montañas mexicanas (SZYSZLO, 1909; en ORTOLL, 1982, p.237). Incluso el ya mencionado ingeniero Eduardo Harcort ${ }^{7}$, hombre de ciencia, aventurero

7 Fue colaborador y más tarde adversario de Santa-Anna. En 1842 Ramón de la Vega le publicó un estudio sobre Colima. Véase Noticias geográfico-políticas del Territorio de Colima escritas por el coronel ingeniero D. Eduardo Harcort, en el año de 1834, y publicadas en 1842 por Ramón de la Vega, Imprenta de S. Pérez, México, 1842 (N. del C.) (pág. 48). Mathieu de Fossey. Por los rumbos de Colima en Por Tierras de Cocos Y Palmeras. 


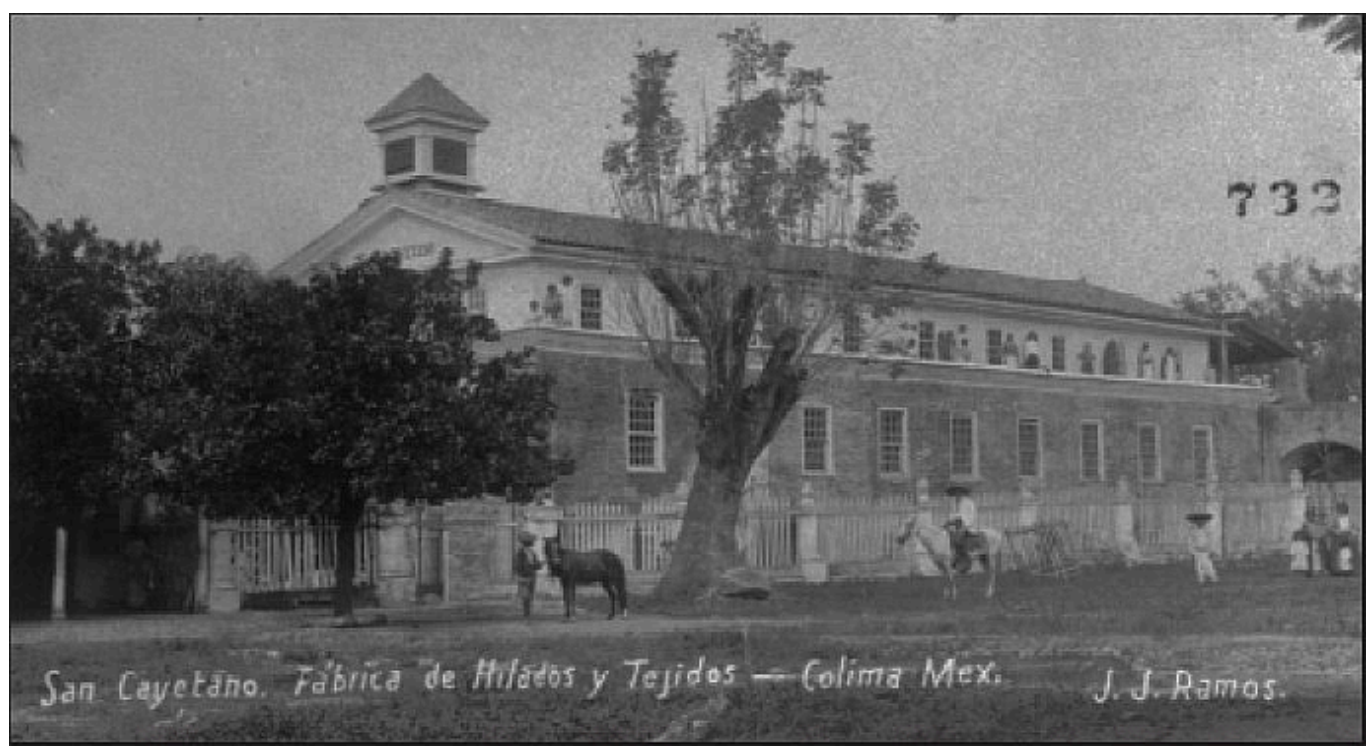

Imagen 3. Fábrica de hilados y tejidos San Cayetano, finales del siglo XIX Fuente: AHMC, Colección fotográfica, J. J. Ramos_AH-407.

y escritor, llegó a México como director de la compañía inglesa Mexican minning Company (FOSSEY, 1857; en ORTOLL, 1982). Las representaciones de abundancia, propiciaron que a mediados del siglo XIX llegara una nueva oleada migratoria a México, principalmente, de alemanes (ACUÑA, MIRTEA y RODRÍGUEZ, s/f), atraídos por la promesa de riqueza.

\section{El paisaje mexicano como objeto de estudio CIENTÍFICO}

HUMBOLDT (1845, p.IV) hablaba de ciencias al referirse al estudio de la botánica, la geología, la química, la astronomía y el magnetismo terrestre. Siendo la ciudad de México, el lugar donde vio un interesante avance al respeto, "ninguna ciudad del nuevo continente, sin exceptuar las de los Estados Unidos, presentaba establecimientos científicos tan grandes y sólidos como la ciudad de México" (KRAUZE, 1994). Además, era evidente que el pensamiento occidental estaba gobernado por la ciencia, es por ello que una tierra novedosa para el naturalista europeo, se convirtió en un lugar que esperaba ser descubierto.

\footnotetext{
Apuntes de Viajeros a Colima, Siglos XVIII a XX. México DF: Instituto José María Luis Mora
} y Offset, 1982.
El conocimiento científico era necesario para esclarecer aspectos que el ojo desnudo y la mente no ilustrada era incapaz de comprender. Paula Kolonitz lo hizo latente en su viaje, al mencionar que "desgraciadamente lo mejor y lo más recóndito quedará para siempre escondido ya que nos faltaba un compañero científicamente instruido", persona que pudiera explicar y denominar las curiosidades naturales que se iban encontrando en el camino. Kolontiz insistió en esta carencia de la visión científica entre la muchedumbre que la acompañaba, "mucho deploramos esto ya en el mar, ya en el continente, porque miles y miles de cosas eran nuevas para nosotros y muchísimas habrán pasado inadvertidas ante nuestros ojos" (KOLONITZ, 1992, p.41).

En otros casos, como por ejemplo en la obra de Sartorius, se distinguió claramente entre los tipos de lectores, entre el hombre de ciencia y el lector común. Sartorios advirtió en su libro, que ha "tratado de ofrecer una descripción de las distintas regiones del país, menos interesantes quizás para el lector común que para los amigos de las ciencias naturales" (COVARRUBIAS, s/f, p.226). Además, él deseaba presentar una perspectiva del paisaje que incluyera a los diferentes grupos de la población, con el fin de que el lector pudiera formarse una idea del entorno junto a las personas y sus relaciones sociales. 


\section{LOS PELIGROS DE LA TROPICALIDAD}

Realizar viajes por México, incluso en el trayecto más transitado, del puerto de Veracruz a la Ciudad de México, se convirtió en sinónimo de peligro. Un sin número de amenazas esperaban a los descuidados viajeros europeos, de tal forma, que enfermedades como la fiebre amarilla, la presencia de insectos desagradables, temblores y fuertes aguaceros formaron parte de los relatos. Pero quizá la mayor preocupación era encontrarse con bandidos, quienes esperaban ocultos en los sombríos bosques de los caminos mexicanos, con el afán de desposeer de sus pertenencias a cualquier incauto.

Madame CALDERÓN DE LA BARCA (1843; 2000, p.44) describió su temor al dirigirse a la ciudad de México desde el puerto de Veracruz, cuando el camino se hacía más montañoso y se cubría de bosques, y a poco distancia de avanzar ella y sus acompañantes se adentraron en un paraje conocido con el nombre de la Selva Negra, gran guarida de bandidos y a la vez hermoso ejemplo de panorama selvático. Lo mismo sucedió en el Cofre de Perote, al cual describió por sus "oscuros y espesos bosques de arrogantes árboles de pinos, sus interyacentes montañas, sus cantiles sombríos y su gigantesco cofre" (CALDERÓN DE LA BARCA, 1843; 2000, p.44).

Heller también hace referencia a las sombrías forestas mexicanas. En su obra, relató cómo los espesos bosques de las regiones más altas rodearon a su comitiva, era un bosque milenario. Heller estaba consciente del peligro que representaba la belleza del bosque, "Ilena el alma del caminante de un cierto temor, que no surge del miedo, sino del abandono sin límites en el que se encuentra y del pensamiento de que perderse en estos bosques lo llevaría sin remedio a la condenación", ya que a causa del transporte de plata, tenían allí su guarida una horda de ladrones. ${ }^{8}$

8 "Apenas hay día en que no exhale su último aliento algún caminante solitario hay lugares en los que cierta cantidad de cruces señala el sitio de un horrible asesinato. Estas tristes huellas de la crueldad humana, el profundo silencio del bosque, el siniestro susurro del viento entre las agujas de los pinos y, con todo, la sublimidad infinita del poder de la naturaleza me causaron tal impresión que no podré olvidad mientras tenga vida." Carl Bartholomaeus Heller. Viajes por México en los años 1845-1848. México DF: Banco de México, 1853. Pág. 168.
Fueron pocos los viajeros que no mencionaron el temor de cruzar un espeso bosque, como si lo indomable de la naturaleza fuera a la vez el mejor aliado del ladrón y del asesino.

\section{LA REPRESENTACIÓN ARTÍSTICA DEL PAISAJE MEXICANO.}

Algo que estuvo patente en las descripciones del paisaje, fueron las apreciaciones de lo bello, en donde los valores estéticos de los viajeros se vieron reflejados en las descripciones que hicieron del paisaje mexicano. De acuerdo con Nagué, los cánones estéticos que rigen la belleza de un paisaje proceden a menudo de los mismos cánones estéticos que se utilizan para valorar una obra de arte. Con frecuencia se califica como bello a un paisaje, cuando consciente o inconscientemente, se reconoce en él, un antecedente avalado artísticamente, por lo tanto, el paisaje es visto como el fiel reflejo de un país, y en su protección confluirán consideraciones de carácter moral y patriótico (NOGUÉ, 2008, p.12-14). Así, los relatos de los viajeros combinaron los ideales de paisaje adquiridos en sus tierras, con uno nuevo, el a veces tropical, a veces desértico, a veces montañoso paisaje mexicano. De tal forma, la búsqueda por europeizar el paisaje, aunado con los esfuerzos de la naturaleza nativa de sobrevivir, constituyeron el nuevo paisaje mexicano que fue plasmado en las obras de los exploradores.

El mismo Humboldt estaba consciente de la influencia de la pintura de paisaje en el estudio de la naturaleza, alegaba que "no es menos a propósito la pintura de paisaje que una descripción fresca y animada para difundir el estudio de la Naturaleza" (HUMBOLDT, 1845, p. 173). Humboldt hacía evidente que los viajeros que hasta el momento habían visitado los trópicos carecían de "una preciosa y larga experiencia de las artes", ya que sus ocupaciones científicas no les permitían espacio para perfeccionar su talento de paisajistas. Muy pocos de ellos, llevados generalmente por el interés que ofrece la botánica al representar formas nuevas de frutos y flores, podían expresar la impresión general producida por el aspecto de los trópicos. Humboldt, agregó que la 
pintura de paisaje no es tampoco puramente imitativa; sino más bien el fruto de la contemplación profunda de la naturaleza y de la transformación que se verifica en el interior del pensamiento (HUMBOLDT, 1845, p.181-183). Por lo que las obras pictóricas del paisaje mexicano popularizados en los escritos de los viajeros, estaban mediadas por la capacidad de contemplación y reproducción de quienes las elaboraban.

Los escritos de viajeros, especialmente aquellos que no poseían una visión científica más allá del ser aficionados, mostraron predilección por cierto tipo de paisaje, en donde la naturaleza era domada y prevalecía el verde y las flores. Paula Kolonitz hacía tan evidente su predilección por el paisaje florido, que su ausencia se lo achacaba al atraso del arte de la jardinería en México ${ }^{9}$. Este fetichismo hacia lo verde es a lo que Venturi ha denominado verdolatría, la cual marca la diferencia entre los valores estéticos (paisajísticos) y los valores ecológicos (medioambientales) ${ }^{10}$. Aunque en el caso de los escritos de viajeros, la distinción fue entre los valores paisajísticos y los científicos. Con referencia a esto último, un botánico, por ejemplo, mostraría más interés en las especies que conforman un paisaje que a la configuración artística y paisajística en sí.

La síntesis de los valores estéticos sobre el paisaje es el jardín, las alusiones hacia él fueron múltiples en los escritos de viajeros. Así, el jardín como poseedor de algunos elementos de la naturaleza, pero organizados a caprichoso del hombre, fue inspiración

9 Ha encontrado que para cultivar las flores aquí se hace mucho menos que en Europa. El arte de la jardinería ha hecho pocos progresos en México a pesar de que podría creerse que este bello país mucho se prestase a ello; pero los jardineros franceses e ingleses, que bajo su cielo han creado tantas bellezas, parece que no han adaptado su sabiduría y sus trabajos al cielo y al clima mexicano. (pág. 129) la irrigación le da a los prados el verde más espléndido y aterciopelado; los más bellos árboles se encuentran magníficamente ordenados; azahares y miles de flores le dan al aire la más balsámica fragancia; las enreordenados; azahares y miles de flores le dan al aire la más balsámica fragancia; las enreMéxico en 1864. México DF: FCE, 1992. Pág. 130.

10 Al espacio verde le importan poco los trazados, las proporciones, los elementos minerales y acuáticos, la composición paisajística o geométrica. Es un nada vegetal reservado a la purificación del aire y al ejercicio físico. (pág. 78). Los italianos denuncian la verdolatría y la reducción del paisaje al spazio verde. Cada vez se tiende más a hablar de "verde" en lugar de jardín y de paisaje. Venturi, 2003, en Joan Nogué. El paisaje en la cultura contemporánea. Buenos Aires, Argentina: Biblioteca Nueva, 2008. Pág. 80. para barrocas descripciones del paisaje ${ }^{11}$. Por ejemplo, Madame Calderón de la Barca, mostró su desprecio hacia el paisaje árido, pero su agrado a la abundancia de flora en su viaje a la ciudad de México, al mencionar que "por fin empezamos a descubrir señales de vegetación: palmeras y flores... y fue como si nos hubieran transportado, por arte de encantamiento, de un desierto a un jardín. El espectáculo era pintoresco y sorprendente a la vez..." (CALDERÓN DE LA BARCA, 1843; 2000, p.29).

Es notorio ver juicios de valor estético en las obras de viajeros, sin embargo, aquellos que buscaban una postura más científica trataron de omitirlos, incluso hicieron evidente lo relativo que puede ser la belleza. Humboldt es el mejor ejemplo de ello, él mencionaba que cada parte de la tierra, tiene también sus bellezas propias; "en los trópicos, la diversidad y la elevación de las formas vegetales; en el Norte, el aspecto de las praderas, y, después de una larga espera, el despertar de la Naturaleza al primer soplo de la Primavera" (HUMBOLDT, 1845, p.185). Esta perspectiva pluriestética, rompía con el estereotipo de belleza del paisaje basado en lo europeo, ampliando su alcance al espacio tropical.

El interés sobre el paisaje mexicano en las ciudades europeas y estadounidenses, pero también en los mismos mexicanos, se reflejó en la abundancia de ediciones y la popularidad de obras que abordaron el tema; por ejemplo la obra de Sartorius, México y los mexicanos hacia $1850 .{ }^{12}$ Parte de su éxito radicó en las láminas incluidas en la publicación desde las primeras ediciones, a cargo del amigo de Sartorius, el pintor Johann Moritz Rugendas, quien también residió en México en la primera mitad del siglo XIX. Estas ilustraciones, junto con el resto de la obra pictórica de Rugendas, se cuentan entre lo más conocido y apreciado del

11 Los senderos que nos rodean sombreados de árboles frutales: áloes, plátanos, chirimoyos, confundidos con el verde liquidámbar, el florido mirto, y centenares de plantas y arbustos y flores de todos los colores, de deliciosa fragancia, todo se combina para formar uno de los espectáculos más variados y bellos que la vista puede contemplar. Madame Calderón de la Barca. La vida en México: Durante una residencia de dos años en ese país. México DF: Editorial Porrúa, 2000. Pág. 34.

12 Este escrito fue originalmente publicado en 1852, pero no bajo este título sino con uno diferente: México. Paisajes y bosquejos sobre la vida del pueblo. José Enrique Covarrubias. "Carl Christian Sartorius y su comprensión del indio dentro del cuadro social mexicano", s/f. Pág. 223-224. 
arte europeo de tema mexicano del siglo XIX (COVARRUBIAS, s/f, p.224).

Las representaciones estéticas del paisaje también fueron elaboradas desde los propios mexicanos, aunque influenciados por la estética europea. Tal fuet el caso de José María Velasco, y la menos conocida Senorina Merced Zamora, pintora que representó al entorno de una pequeña ciudad del occidente de México. Pese a la posición social de su familia, Senorina creció en un contexto que limitaba la educación a las mujeres, aunque esto no impidió que mostrara temprano interés en el dibujo natural y de paisaje. ${ }^{13}$ Posteriormente, Senorina ingresó a la Escuela Nacional de Bellas Artes, en donde fue discípula de José María Velasco en la década de los noventa del siglo XIX (VELÁZQUEZ, 2000, p.23). En dicha institución, la joven pintora no tuvo otra opción que especializarse en paisaje, ya que a pesar de que la escuela abrió sus puertas a las mujeres en el año de 1888, ellas fueron excluidas de la clase de dibujo del natural y el estudio formal de la anatomía humana. ${ }^{14}$ La obra de Senorina fue expuesta y galardonada en la Exposición Universal de París de 1889 y en la Exposición Internacional de Chicago de 1893 (RAMÍREZ Y BADILLO, 1996, p.56). En general, Senorina representó al paisaje ribereño en sus obras, especialmente a los baños públicos, la vegetación, los volcanes de Colima, casas habitación, entre otros elementos (Imagen 4).

\section{Conclusiones (LA EUROPEIZACIÓN del PAISAJE MEXICANO)}

De acuerdo con la perspectiva de BESSE (2011, p.10), las representaciones del paisaje presentadas en este artículo, cumplen con algunas de las características de la concepción clásica del paisaje, es decir, coloca a la visión en un nivel superior a los otros sentidos, además corresponde a una perspectiva cultural blanca, europea, occidental, y no toma en cuenta otros modelos culturales relacio-

13 NYPU, 1842, Noticias geográfico-políticas del Territorio de Colima por Eduardo Harcort. Pág. 20.

14 Alrededor de 1888, la Academia registró los primeros nombres de mujeres enroladas como estudiantes regulares, sin embargo, las distinciones de género impidieron que pudieran aspirar a cursos distintos al paisajismo. En Velázquez Guadarrama, 2001. Pág. 129 nados con el paisaje, es esencialmente masculina (aunque en este artículo se incluyó la perspectiva de tres mujeres), y finalmente, las representaciones de los paisajes estuvieron asociadas a la colonización de nuevos territorios.

El paisaje en América tuvo modificaciones importantes a partir de la llegada de los europeos, quienes se toparon con vegetación exuberante y de exóticas formas, con animales que parecían haber escapado de relatos mitológicos, y con paisajes americanos que fueron vistos con una mezcla de estupor y desconfianza. Incluso, un humanista español de la época, hablaba de "dar a aquellas tierras extrañas la forma de la nuestra" (ANZOLIN, 2006, p.33). Aunado a lo anterior, se introdujeron a América muchos vegetales y granos, como el trigo, la cebada, el arroz, el centeno, vides, garbanzos, lentejas, almendros, naranjos, limoneros, perales, romeros, castaños y multitud de flores; y también animales como caballos, bueyes, mulas, vacas, cabras, cerdos y ovejas (ANZOLIN, 2006, p.33); que pronto se adhirieron al ambiente mexicano, lo cual dio como resultado un nuevo paisaje que ya no era americano, pero tampoco europeo.

La destrucción del paisaje nativo fue evidente, Kolonitz lo evidenció al decir que los españoles fueron siempre enemigos de las florestas y de los bosques, que sus devastadoras manos pasaron por las tierras mexicanas, causando grandes daños a la irrigación del valle, al hacer que los lagos cada día se evaporaban más y más, secando las fuentes y haciendo del terreno un lugar árido. Además, Kolonitz agregó, que cuando los conquistadores llegaron al país, el planalto del Anáhuac tenía bosques y magníficas selvas, estaba cubierto de encinos, cedros y cipreses (KOLONITZ, 1992, p.84). Con ese tipo de descripciones, esta mujer austriaca estaba consciente del cambio del paisaje, y señalaba culpables, en este caso los españoles.

Los escritos de viajeros también contribuyeron a la construcción de nacionalidades, los criollos mexicanos llegaron a leer el célebre ensayo de Humboldt publicado en 1811, más como una profecía nacional que como un libro científico. Fue así que se esparció la idea de que el vasto reino de la Nueva España, bien cultivado, produciría por sí solo todo lo que el comercio buscaba 


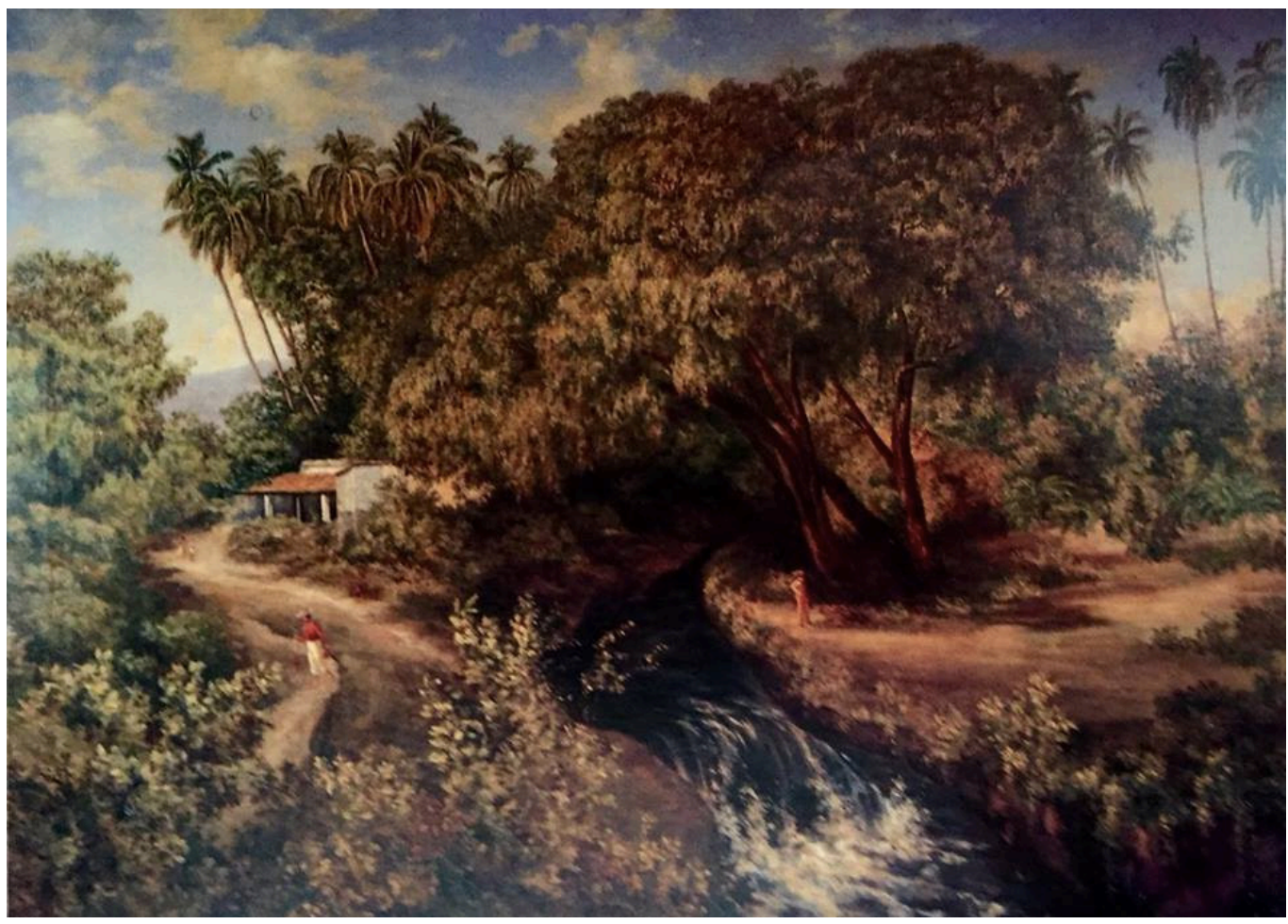

Imagen 4. Sauces en la ribera del río Colima por Senorina Merced Zamora en 1898 Óleo/tela, 52.2x66 cm. En Juan Carlos Reyes, Senorina Merced Zamora, el arte de pintar. 2000. p.42.

en el resto del globo, el azúcar, la cochinilla, el cacao, el algodón, el café, el trigo, el cáñamo, el lino, la seda, los aceites y el vino; así como todos los metales, sin excluir al mercurio. Además de sus excelentes maderas de construcción y la abundancia de hierro y cobre que favorecerían los progresos de la navegación mexicana (KRAUZE, 1994, p.21). De esta forma, el paisaje mexicano daba esperanza a una nación acabada de nacer, prometiendo abundantes recursos naturales que harían progresar al país.

Sin embargo, el intercambio no fue recíproco. A pesar de que también América aportó diversos productos a Europa, en un inicio, las especies americanas no fueron tan fácilmente aceptadas en el Viejo Continente. Por ejemplo, el tomate fue sospechado de venenoso, al igual que la papa, la cual se prohibió porque no estaba descrita en la Biblia (ANZOLIN, 2006, p.34). La europeización no solo se limitó al paisaje, sino también afectó a los humanos que hasta el momento habían contribuido a forjarlo. Al respecto,
Guillermo Prieto en 1864 señaló que no se permitirían comentarios como los realizados por Fossey, viajero francés que señalaba la necesidad de blanquear al país a través del mestizaje, o mediante un fuerte incremento de la población de raza blanca, cuyo predominio numérico acabaría por imponer su modo de vida al de los "atrasados indios", y dar fin a sus "toscas" manifestaciones culturales (FERRER, s/f, p.121). Incluso se señaló que el "atraso" de los nativos se debía al paisaje, un entorno que no daba cabida al desarrollo. Este aspecto fue mencionado en la obra de Sartorius, quien aseguraba que uno de los rasgos distintivos de México hacia 1850 fue la gran importancia que en él se le dio al medio físico como escenario de la vida y las actividades de la población mexicana. Esta atención no fue exclusiva de Sartorius, pero él atendió la estrecha correspondencia entre los aspectos físicos y morales del país. Entonces, de acuerdo con este autor, el paisaje vino a ser una "unidad orgánica integradora del elemento hu- 
mano en sus perfiles materiales y morales" (COVARRUBIAS, s/f, p.224-225).

El resultado de todo esto, fue el paisaje mexicano visto desde la perspectiva europea de mediados del siglo XIX, caracterizado por una serie de representaciones que se propagaron mediante los escritos de viajeros. Fue así, que México fue visto como una nación donde el paisaje tropical reinaba; condición que hacía incómoda la estancia de los europeos, por el calor, la humedad, las enfermedades y los insectos, además de que se creía que la espesa y sombría selva estaba plagada de ladrones y mercenarios. Pero aún así, los europeos seguían siendo atraídos por la imagen de un paisaje exótico, lleno de nuevas criaturas, un pueblo "atrasado" pero con un pasado milenario, y probablemente lo más atractivo, una tierra fértil rebosante de recursos naturales que esperaba por personas que buscaban fortuna y una nueva vida.

\section{ReferênCIAS Bibliográficas}

ACUÑA, Mirtea E., \& Rodríguez, Pablo. "Ana Amalia Schacht Gamiochipi: colimense y alemana. Universidad de Colima.", 2004

ANZOLIN, Adriana. Lazos verdes. Buenos Aires, Argentina: Editorial Maipue, 2006. BECK, Hanno. Alexander Von Humboldt. México DF: FCE, 1971.

BERQUE, Agustin. "En el origen del paisaje". Revista de Occidente, 1997, 7-21.

BERQUE, Agustin. El pensamiento paisajero. Madrid, España: Biblioteca Nueva, 2009. BESSE, Jean-Marc. "El espacio del paisaje". Facultad de Humanidades y Ciencias de la Educación, Universidad Nacional de La Plata, 2010.

BESSE, Jean-Marc. "L'espace du paysage. Considérations théoriques". En Théorie et paysage: réflexions provenant de regards interdisciplinaires, Observatorio del Paisaj de Cataluña., 7-24. Observatori del Paisatge y Universitat Pompeu Fabra, 2011.

BESSE, Jean-Marc. "Las cinco puertas del paisaje. Ensayo de una cartografía de las problemáticas paisajeras contemporáneas." En Paisaje y pensiamiento, Javier Maderuelo., 145-71. Abada editores/CDAN, 2006.

BESSE, Jean-Marc. La sombra de las cosas. Sobre paisaje y geografía. Madrid, España: Biblioteca Nueva, 2010.

BIBLIOTECA NACIONAL DE CHILE (BNC), Patrimonio cultural común, Vegetation of the westcoast, Palm-wood and volcano of Colima, Mauricio Rugendas 1840, id MC: MC0007347, en http://www.memoriachilena.cl/602/w3-article-67979.html

CALDERÓN DE LA BARCA. La vida en México: Durante una residencia de dos años en ese país. México DF: Editorial Porrúa, 2000.

COVARRUBIAS, José Enrique. "Carl Christian Sartorius y su comprensión del indio dentro del cuadro social mexicano", s/f.
CHAVERO, Alfredo. "Obras del Lic. Don Alfredo Chavero-tomo I.", 1864.

FERRER, Manuel. "Mathieu de Fossey: su visión del mundo indígena mexicano", s/f. GROHNERT, Sebastián Schoennenbeck. "Paisaje, nación y representación del sujeto popular. Visiones de un Chile imaginado". Aisthesis 53 (2013): 73-94.

HARCORT Eduardo. "Ensayo estadístico sobre el territorio de Colima por la muy ilustre municipalidad de la capital del mismo territorio", 1831. Archivo Histórico de Estado de Colima.

HELLER, Carl Bartholomaeus. Viajes por México en los años 1845-1848. México DF: Banco de México, 1853.

HUMBOLDT von, Alexander. Cosmos. Berlín, 1845.

JACKSON, John Brinckerhoff. Discovering the vernacular landscape. Estados Unidos: Yale University Press, 1984.

JODELET, Denise. "La representación social: fenómenos, conceptos y teorías." En Psicología social I: influencia y cambio de actitudes, individuos y grupos, 470. Barcelona, España: Paidós, 1985

KOLONITZ, Paula. Un viaje a México en 1864. México DF: FCE, 1992

KRAUZE, Enrique. "Humboldt y México un amor correspondido". Vuelta 212 (julio de 1994).

New York Public University (NYPU), 1842, Noticias geográfico-políticas del Territorio de Colima escritas por el coronel ingeniero D. Eduardo Harcort en el año de 1834 y publicadas en 1842 por Ramón de la Vega.

NOGUÉ, Joan. El paisaje en la cultura contemporánea. Buenos Aires, Argentina: Biblioteca Nueva, 2008.

ORTOLL, Servando. Por tierras de cocos y palmeras. Apuntes de viajeros a Colima siglos XVIII a XX. México, DF: Instituto José María Luis Mora y Offset, 1982.

RAMÍREZ, José Luis y Badillo, Ofelia. Senorina: Éxtasis de la plástica colimense. Colima, México: Gobierno del Estado de Colima: Instituto colimense de cultura, 1996. REYES, Juan Carlos. Senorina Merced Zamora, el arte de pintar. Colima, México: Gobierno del Estado de Colima y Universidad de Colima, 2000.

RIVERA, Manuel. México pintoresco artístico y monumental: vistas, descripción anécdotas y episodios de los lugares más notables de la Capital y de los Estados, aun de las poblaciones cortas, pero de importancia geográfica o histórica. México: Imprenta de la Reforma, 1882

VELÁZQUEZ, Angélica. "Las primeras discípulas de la Escuela Nacional de Bellas Artes: El caso de Merced Zamora". In: Senorina Mercedes Zamora. El arte de pintar. Colima: Gobierno del Estado de Colima;Universidad de Colima, 2000. 
Juan Pablo Angulo Partida

Universidad de Colima, Facultad de Ciencias Políticas y Sociales.

Avenida Universidad 333, Las Víboras, 28040 Colima, Col. Mexico.

https://orcid.org/0000-0002-6623-5211

angulo.ciages.2011@gmail.com

Nota del Editor:

Sumisión: 16/08/2018

Aceptado: 19/01/2020 